\title{
Estimation on the Field Application for In-Site Recycling of the Wastes Soil from Preboring
}

\author{
Baek-Joong Kim ${ }^{1}$ and Heebok Choi ${ }^{2}$ \\ ${ }^{1}$ School of Civil, Environmental and Architectural Engineering, Korea University, Anam-dong, Seongbuk-gu, \\ Seoul 136-713, Republic of Korea \\ ${ }^{2}$ Department of Architectural Engineering, Jeju National University, 102 Jejudaehakno, Jeju-si, Jeju-do 690-756, Republic of Korea
}

Correspondence should be addressed to Heebok Choi; chb0319@jejunu.ac.kr

Received 16 November 2015; Revised 15 February 2016; Accepted 17 February 2016

Academic Editor: Wenbin Yi

Copyright (C) 2016 B.-J. Kim and H. Choi. This is an open access article distributed under the Creative Commons Attribution License, which permits unrestricted use, distribution, and reproduction in any medium, provided the original work is properly cited.

\begin{abstract}
The design criteria for a structural foundation with soil cement injected precast piles (SIP) indicate that the cement milk gains a conservatively high compressive strength. In addition, a certain amount of the cement milk is lost to the surrounding soil as a result of the high water-cement ratio. Furthermore, the cost increases since the material needs to be exported to the outside of the construction site to dispose of the waste soil. This study was carried out to develop a new mixing method to replace a portion of the cement milk with site soil and a cement hardener. The applicability of this method was confirmed by examining the basic physical characteristics of the new material by on-site conducting dynamic pile loading and bond capacity tests. The test results indicate that the new filling material reduced the bleeding and reduced the loss of filling material when compared to cement milk, but the compressive strength and the results of the dynamic pile loading and bond capacity tests were lower than those obtained for cement milk. However, the new filling material satisfies the standard criterion for structure design, and the economic benefits of implementing the proposed method, including saving on the amount of cement used and reducing the costs of transporting waste soil, were confirmed.
\end{abstract}

\section{Introduction}

The allowable exhaust standard for noise and vibration generated by piling construction has recently become more stringent for urban construction, so prebored precast piling methods that make use of pretensioned spun high strength concrete (PHC) piles have been implemented in approximately $2 / 3$ of piling construction sites in Korea [1]. The soil cement injected precast pile (SIP) method is a prebored precast piles method that requires the removal of large volumes of waste soil (about 1,843 ton/day) during excavation, and the transportation and disposal cost of waste soil is one of the factors that increases the total cost of construction.

The bearing capacity of prebored precast piles is calculated according to both the end bearing capacity and the skin frictional capacity, and these bearing capacities are affected by geotechnical conditions ( $N$ value, collapse of a hollow wall, and conditions of underground water) and construction conditions (the amount and components of used cement milk, impact energy, and penetration) [2]. The use of cement milk has been intended to fix the PHC pile that is inserted as well as to ensure the presence of the skin friction force. However, since cement milk has a higher water-cement ratio of about $30 \%$ than that of normal cement paste and does not mix with aggregates, cement milk often leaks into the ground after a period of time, often generating voids between the pile and the surface of the bored hole. These voids affect the skin frictional resistance [3], and cement milk consisting of a high water-cement ratio exhibits a remarkable difference in compressive strength that depends on the location of the upper and lower piles [4]. In the case where soil cement is used as a skin fixative in SIP, the mixing ratio has no clear criterion. Soil cement as a skin fixative is only mixed to ensure a compressive strength of the $0.5 \mathrm{MPa}$ at an age of 28 days with a water-cement ratio of $80 \%$ or more $[4,5]$. Therefore, when compared with the performance requirements of soil cement, 
TABLE 1: Mix proportion [per $1 \mathrm{~m}^{3}$ ].

\begin{tabular}{lccccc}
\hline Filler type & Waste soil & Cement & Solidifying agent & Water & Superplasticizer \\
\hline New filling material & $1,062 \mathrm{~kg}$ & $250 \mathrm{~kg}$ & $0.625 \mathrm{~kg}$ & $340 \mathrm{~kg}$ & $0.3 \%$ \\
Cement milk & - & $880 \mathrm{~kg}$ & - & $730 \mathrm{~kg}$ & - \\
\hline
\end{tabular}

the use of cement milk is very uneconomical due to the unnecessary strength development as well as the occurrence of voids and inhomogeneous compressive strength according to the depth of the hole.

In order to recycle on-site waste soil produced in construction, fundamental laboratory experiments to measure fluidity, bleeding, and unconfined compressive strength have been carried out in order to ensure optimum constructability. Moreover, the applicability of the mixture method in the field was assessed by carrying out on-site dynamic pile loading and bond capacity tests for PHC pile construction.

\section{Experimental Program}

2.1. Optimization of Waste Soil Material. Since waste soil produced in construction is composed of particles of various sizes and there small stones are also broken during boring, it is difficult to recycle all of the waste soil that is generated on site. The waste soil is very moist, and it contains varying levels of water content depending on the level of the groundwater, even within the same site. Therefore, sieve clogging and a pipe blockage can occur during pumping, so the waste soil should be selected to be as small as the size of the sieve. On the other hand, the coarse particles should be considered to achieve the designed compressive strength gain in the material [6]. The cumulative percentage passing of the waste soil according to the sieve type and the moisture contents is shown in Figure 1. Since the waste soil passing through a number $4(4.75 \mathrm{~mm})$ sieve showed a satisfactory lumpy phenomenon of the soil or blockage phenomenon of the sieve, this study used the waste soil in a natural state passing through a number $4(4.75 \mathrm{~mm})$ sieve. Under the conditions of both lumpy phenomenon of soil and blockage phenomenon of the sieve, the waste soil passed through a $9.5 \mathrm{~mm}$ sieve is satisfying the good condition close to the required performance than when it passed through a number $4(4.75 \mathrm{~mm})$ sieve. But the waste soil passed through a number $4(4.75 \mathrm{~mm})$ sieve is more effective in controlling the clogging of the pipe with inner diameter $30 \mathrm{~mm}$ under pumping work [7].

2.2. Mix Proportions. The mix proportion of the new filling material (Table 1) was modified from preliminary experiments and another research result [8] in order to fit the fluidity required for the soil properties of the field. The mix proportion of the cement milk is the same as that generally applied in the field. In the case of the new filling material, both the unit water content and the superplasticizer were determined in order to satisfy the flow value of the constructability [9].

A new solidifying agent was developed with various chemical compounds, including those of the carbon group, nitrogen group, and iron group, and the composition of the

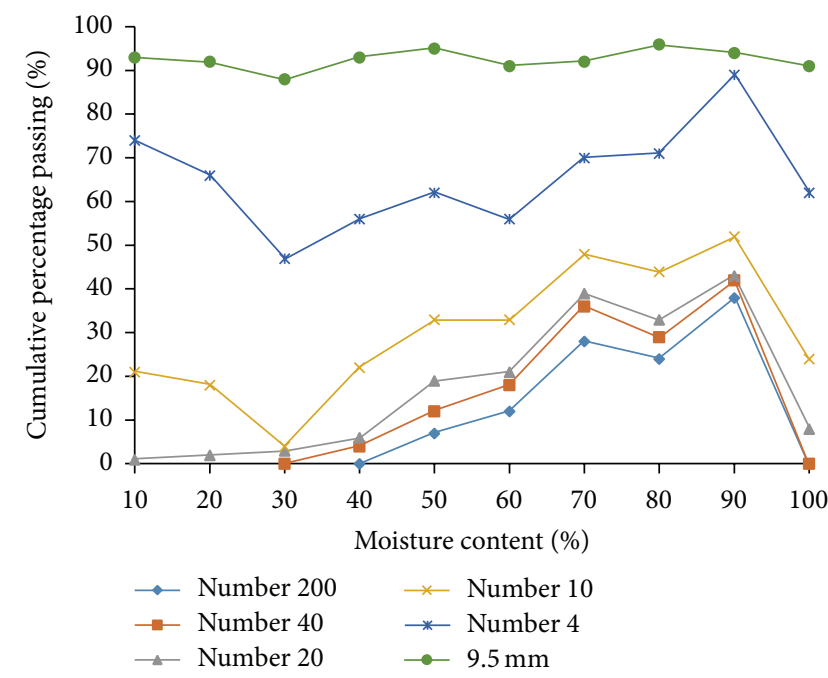

FIGURE 1: Sieve passing percentage according to both moisture content and particle distribution.

TABLE 2: The components composition of the new solidifying agent.

\begin{tabular}{lcccc}
\hline $\begin{array}{l}\text { Components } \\
\text { composition }\end{array}$ & $\begin{array}{c}\text { Sodium } \\
\text { chloride }\end{array}$ & $\begin{array}{c}\text { Potassium } \\
\text { chloride }\end{array}$ & $\begin{array}{c}\text { Magnesium } \\
\text { chloride }\end{array}$ & $\begin{array}{c}\text { Other } \\
\text { substances }\end{array}$ \\
\hline Content $(\%)$ & 16 & 35 & 22 & 27 \\
\hline
\end{tabular}

new solidifying agent is shown in Table 2. The addition of a new solidifying agent to waste soil containing a lot of moisture results in the exchange of calcium ions generated by the hydration reaction of calcium hydroxide with ions in the clay mineral (kaolinite, montmorillonite, silicon dioxide, and aluminium oxide) [10]. The pozzolanic reaction is a secondary chemical reaction that starts, and the material is solidified and stabilized over time. In other words, since the new solidifying agent can be used as a water-soluble material by mixing water or spraying with an aqueous solution, it can easily penetrate between the soil particles, and the activated film of the surface of the organic soil particles is thus chemically treated. Accordingly, the arrangement between the soil particles stabilizes, and the setting effect of the cement is enhanced.

2.3. Fluidity and Bleeding. The fluidity of the new filling material was evaluated by using a cylinder mould with a diameter of $80 \mathrm{~mm}$ and a height of $80 \mathrm{~mm}$ according to the JHS A313 standard [11]. The segregation resistance was observed from the relative degree of separation of water from the materials 3 hours after placing $500 \mathrm{~mL}$ of each mixed material into a mass flask and sealing the mouth of the flask 


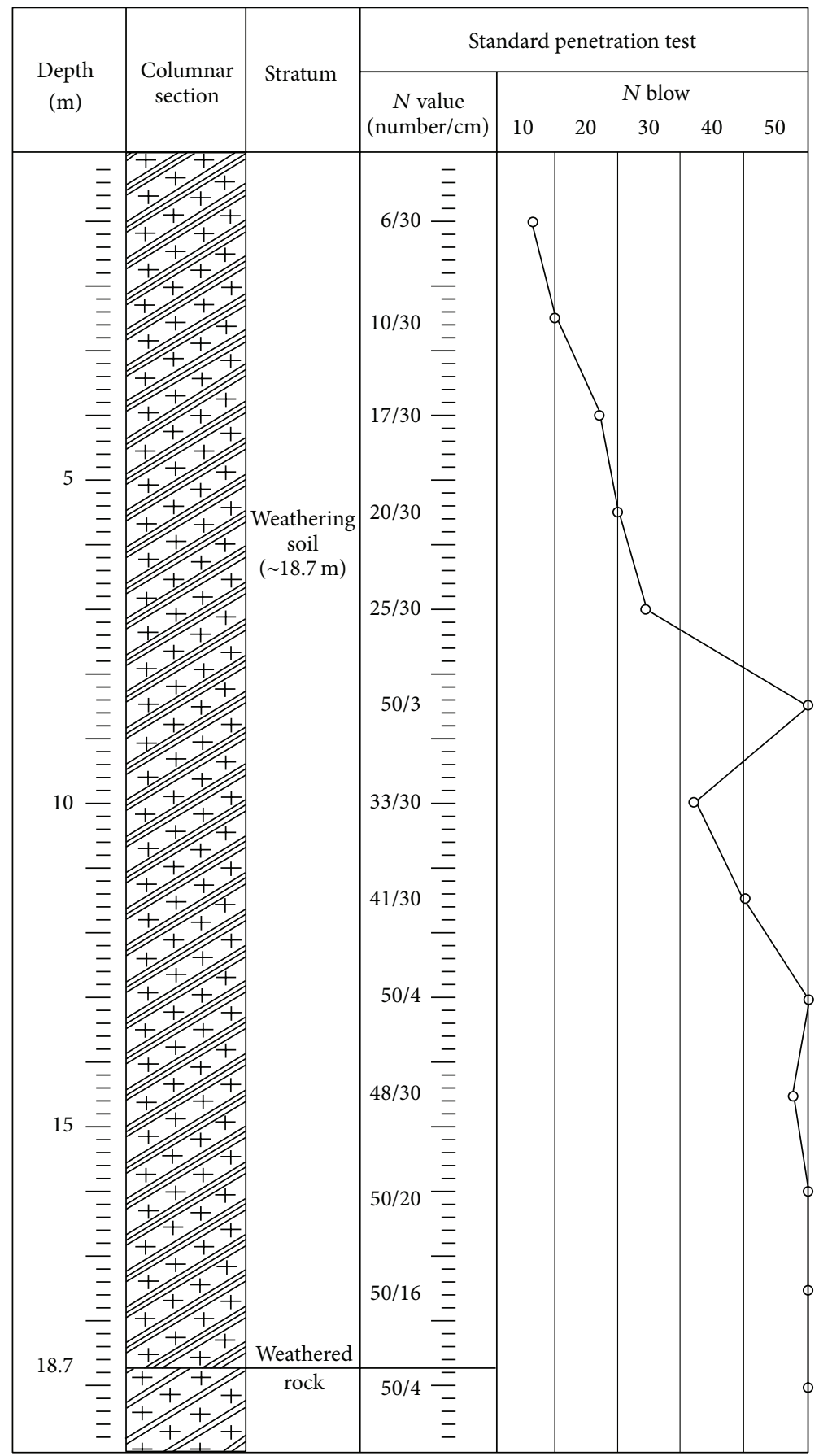

FIGURE 2: Soil profile sample of the construction site at which the experiment is applied.

to prevent the evaporation of water, as specified in the ASTM C940 standard [12].

2.4. Specimen for Unconfined Compressive Strength. A total of 24 specimens, 3 specimens per filling material, were prepared for the compressive strength test, and the specimens were tested at 3 days, 7 days, 14 days, and 28 days after atmosphere curing.
2.5. Set-Up and Measurement for On-Site Test. The testing site is located in Busan, Korea, and a soil survey of the site was conducted with a total of 60 survey points. Figure 2 shows the soil profile samples of the actual construction site where the experiment was carried out. From the results of the boring investigation, the stratum configuration state was largely made up of weathering soil and a weathered rock layer, and the underground water level was located at GL (-) $5.0 \sim 8.5 \mathrm{~m}$. 

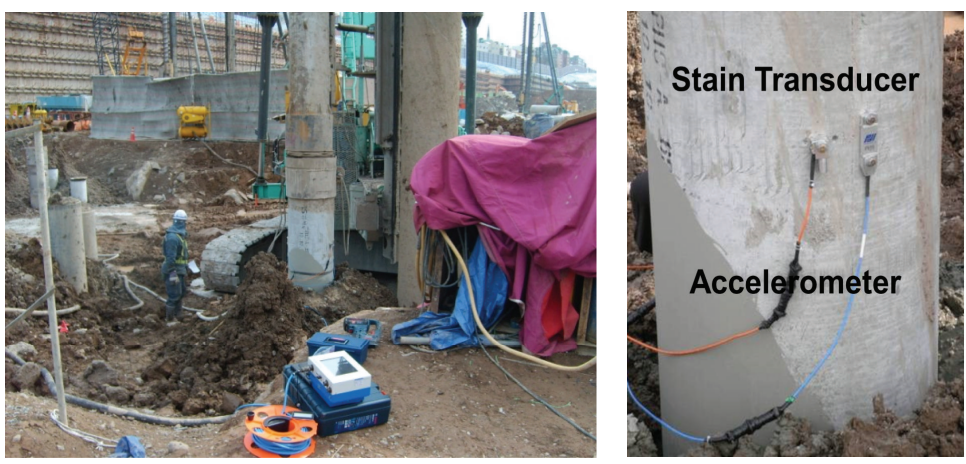

FIGURE 3: Schematic set-up of dynamic pile loading test.

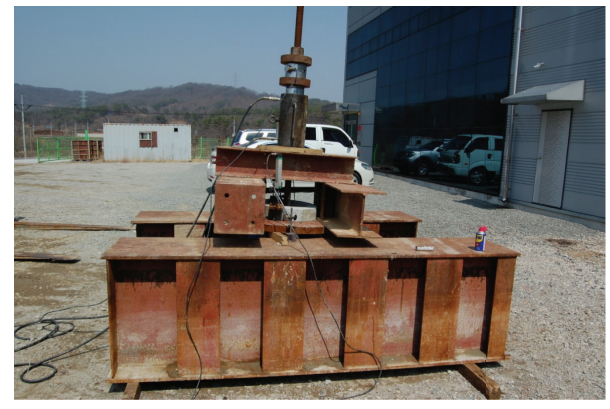

FIGURE 4: Set-up of the specimen for the bond capacity test.

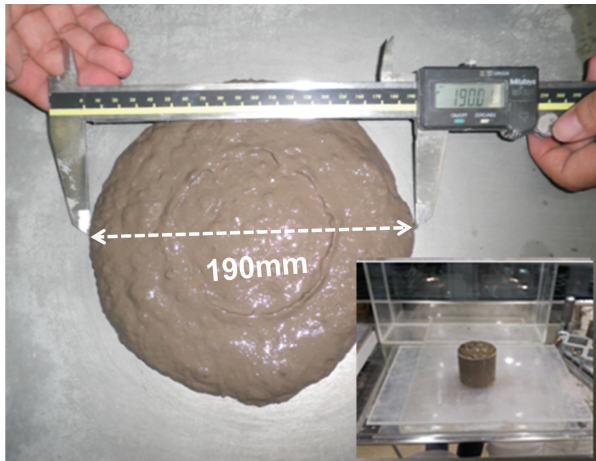

FIGURE 5: Slump flow assessment of the new filling material.
A total of two piles were used in the field test. Both piles used in this experiment are PHC piles with a diameter of $0.6 \mathrm{~m}$, pile lengths of $11.0 \mathrm{~m}$, and penetration depth of $9.0 \mathrm{~m}$. To ensure an evaluation under the same conditions, two filling materials were injected up to $2.0 \mathrm{~m}$ below the upper part of the end of the pile. In the case of the cement milk, an additional material was injected due to the loss of the cement milk.

The dynamic pile loading test was conducted by following the ASTM D4945-00 Standard Test Method for high strain dynamic testing of piles. The end of the initial driving for all specimens was performed on the same day, and the restrike test was then carried out after seven days. The specifications and the schematic set-up for the dynamic pile loading test are shown in Table 3 and Figure 3.

The specimen for the bond capacity test was designed in order to evaluate the difference in the shear characteristics between the PHC pile and the filling materials, as shown in Figure 4 . The specimen was manufactured by inserting a $\mathrm{PHC}$ pile with a diameter of $450 \mathrm{~mm}$ and a height of $1.0 \mathrm{~m}$ and by inserting a tension bar with a diameter of $50 \mathrm{~mm}$ inside the PHC pile within the PVC cylinder with a diameter of $650 \mathrm{~mm}$ and a height of $950 \mathrm{~mm}$. The empty space between the PVC pipe and the PHC pile was filled with the new filling material and cement milk, respectively. A total of 6 specimens were prepared, 3 specimens with the new filling material and 3 specimens with the cement milk.

\section{Results and Discussion}

3.1. Fluidity and Bleeding. As reported by Miki et al. [13], the flow value for the liquidity must be $150 \sim 250 \mathrm{~mm}$ under a cylinder mould of $\varnothing 80 \mathrm{~mm} \times 80 \mathrm{~mm}$. As shown in Figure 5, the slump flow value of the new filling material is $190 \mathrm{~mm}$, and this value is considered to be appropriate to fill the narrow spaces between the structures and/or vacant spaces in the ground without the need for compaction.

Since a backfilling material has high unit content of water, the bleeding phenomenon may occur in which water floats up to the surface. According to Miki et al. [13], less material segregation occurs at a bleeding rate of less than $1 \%$. In addition, a bleeding test (JSCE F522) [14] can be conducted to confirm that the bleeding rate is less than $1 \%$ at three hours after placement. As shown in Figure 6(a), bleeding did not occur in the new filling material. However, Figure 6(b) shows that bleeding of about $10 \mathrm{~mL}$ occurred with the cement milk, and the amount of bleeding is about $2 \%$ of the total $500 \mathrm{~mL}$ that was injected into the mass flask. Bleeding of about $2 \%$ is a significant amount considering a pile length of tens of meters, and with a bleeding of $2 \%$, the transfer of the structural load between the pile and the vacant spaces in the upper portion of the pile can be disrupted.

3.2. Unconfined Compressive Strength. The backfilling materials must have sufficient strength to transmit the structural 
TABLE 3: Specifications for dynamic pile loading test.

\begin{tabular}{|c|c|c|c|c|c|}
\hline Type & $\begin{array}{c}\text { Pile } \\
\text { diameter } \\
(\mathrm{m})\end{array}$ & $\begin{array}{l}\text { Embedment } \\
\text { depth }(\mathrm{m})\end{array}$ & Hammer type & $\begin{array}{c}\text { Drop height } \\
\text { of hammer } \\
(\mathrm{m})\end{array}$ & Test type \\
\hline Cement milk & \multirow{4}{*}{0.6} & \multirow{4}{*}{9.0} & \multirow{2}{*}{ Drop 5.0 ton } & 2.0 & End of initial driving \\
\hline New filling materials & & & & 2.0 & End of initial driving \\
\hline Cement milk & & & \multirow{2}{*}{ DKH 7.0 ton } & 1.0 & Restrike \\
\hline New filling materials & & & & 1.0 & Restrike \\
\hline
\end{tabular}

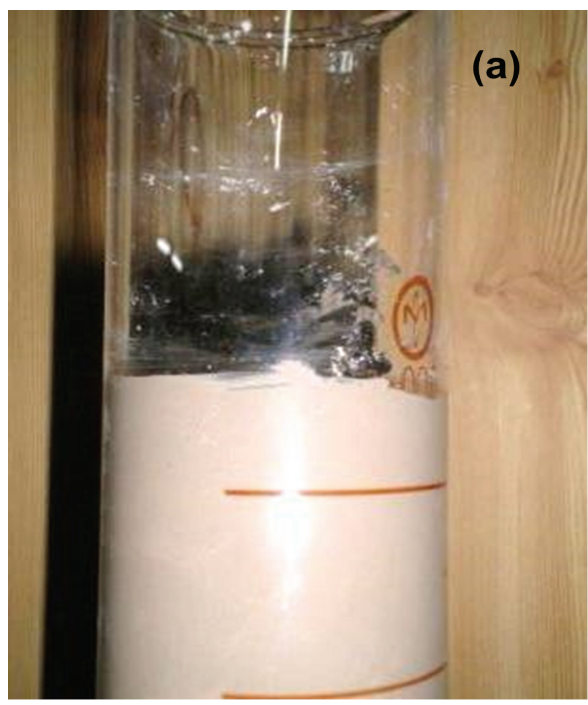

(a)

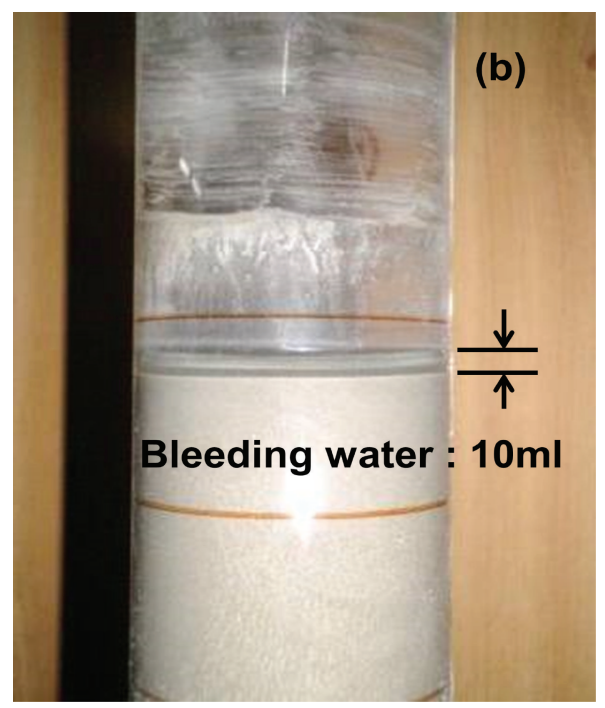

(b)

Figure 6: Bleeding of the new filling material (a) and cement milk (b).

TABLE 4: Compressive strength results according to filling materials.

\begin{tabular}{lcc}
\hline \multirow{2}{*}{ Curing } & \multicolumn{2}{c}{ Compressive strength (MPa) } \\
& Cement milk & New filling material \\
\hline 3 days & 4.32 & 2.65 \\
7 days & 6.25 & 3.89 \\
14 days & 9.16 & 6.12 \\
28 days & 10.45 & 7.23 \\
\hline
\end{tabular}

load on the liquefied soil into the surrounding ground and liquidity to fill the spaces. This strength means there is a greater shearing strength than that of the surrounding ground and a compressive strength that is sufficient to avoid consolidation due to the overburden pressure. According to Miki et al. [13], the unconfined compressive strength for backfilling must be of $0.15 \sim 0.3 \mathrm{MPa}$ when considering reexcavation. Moreover, the Expressway and Transportation Research Institute [15] reported that the unconfined compressive strength for filling materials used with the injected precast pile method must be more than $0.5 \mathrm{MPa}$. The unconfined compressive strength of the new filling material was to a lower level than that of cement milk, as shown in Table 4. However, according to the specifications in Japan and Korea for backfilling, the cement milk shows a higher compressive strength value than what is necessary due to the use of a large amount of normal Portland cement. On the other hand, the new filling material showed a more economical compressive strength while satisfying the reliability requirements and thus reducing the amount of cement necessary compared to the method using cement milk [16].

3.3. Dynamic Pile Loading Test. A driveability analysis was carried out for the PHC piles where the cement milk and the new filling material were used at the end of the initial driving and restrike, and the results are shown in Table 5. The results indicate that the maximum compressive strength at the end of the initial driving for the new filling material and the existing cement milk was $0.203 \mathrm{ton} / \mathrm{cm}^{2}$ and 0.283 tonf $/ \mathrm{cm}^{2}$, respectively. The maximum compressive strength values are within the allowable pile driving stress of 0.480 tonf $/ \mathrm{cm}^{2}$ for the PHC pile, while the material stress due to the pile driving was found to be within the allowable stress. In addition, the pile driving energies of the new filling material and the existing cement milk are 3.2 tonf/m and 3.1 tonf/m, respectively, and this is considered to be a satisfactory stress state for effectiveness of about $40 \%$. Also, the results of the restrike driveability analysis indicate that the maximum compressive stress (CSX) for the new filling material and cement milk was 0.421 tonf $/ \mathrm{cm}^{2}$ and 0.333 tonf $/ \mathrm{cm}^{2}$, respectively. The test 
TABLE 5: Driveability analysis result of the dynamic pile loading test.

\begin{tabular}{lccccc}
\hline Type & $\begin{array}{c}\text { Final penetration depth } \\
(\mathrm{mm})\end{array}$ & CSX (tonf $\left./ \mathrm{cm}^{2}\right)$ & TSX (tonf/ $\left.\mathrm{cm}^{2}\right)$ & EMX (tonf/m) & Test type \\
\hline Cement milk & 2.0 & 0.283 & 0.010 & $3.1(39)$ & End of initial driving \\
New filling materials & 4.0 & 0.203 & 0.015 & $3.2(40)$ & End of initial driving \\
Cement milk & - & 0.421 & 0.015 & $6.7(95.7)$ & Restrike \\
New filling materials & - & 0.333 & 0.011 & $5.2(74.3)$ & Restrike \\
\hline
\end{tabular}

TABLE 6: CAPWAP analysis results.

\begin{tabular}{|c|c|c|c|c|c|c|}
\hline Type & $\begin{array}{c}\text { Skin friction } \\
\text { resistance (tonf) }\end{array}$ & $\begin{array}{l}\text { End bearing } \\
\text { capacity (tonf) }\end{array}$ & $\begin{array}{l}\text { Whole bearing } \\
\text { capacity (tonf) }\end{array}$ & Safety factor & $\begin{array}{l}\text { Allowable bearing } \\
\text { capacity (tonf) }\end{array}$ & Test type \\
\hline Cement milk & 12.0 & 128.6 & 140.6 & \multirow{4}{*}{2.5} & 56.2 & End of initial driving \\
\hline New filling materials & 11.0 & 71.0 & 82.0 & & 32.8 & End of initial driving \\
\hline Cement milk & 68.2 & 141.8 & 209.9 & & 84.0 & Restrike \\
\hline New filling materials & 48.7 & 121.4 & 170.1 & & 68.0 & Restrike \\
\hline
\end{tabular}

values were satisfied within the allowable driving stress of 0.480 tonf $/ \mathrm{cm}^{2}$ of the PHC piles, and the stress of materials was found to be within the allowable stress. The driving energy (EMX) that was measured during pile driving was 5.2 and 6.7 tonf $/ \mathrm{m}$, and the energy efficiency was determined to be as good as $74.3 \%$ and $95.7 \%$ for the new filling material and cement milk, respectively.

A case pile wave analysis program (CAPWAP) was used to measure the initial driving that occurs when a 5.0-ton hammer is dropped and 7.0-ton restrike by a hydraulic hammer; the results of the analysis are shown in Table 6. The average unit frictional resistance of the new filling material consisting of waste soil was of $7.94 \mathrm{tonf} / \mathrm{m}^{2}$, and this value was lower than 8.35 tonf $/ \mathrm{m}^{2}$ of the existing cement milk. However, since the 7.94 tonf $/ \mathrm{m}^{2}$ value is larger than that obtained from the $\mathrm{fs} \leq 0.1$ $\times \mathrm{Ns}\left(\leq 5.0\right.$ tonf $/ \mathrm{m}^{2}, \mathrm{Ns}=$ standard penetration test) equation for the structure foundation design, as proposed by the Korea Geotechnical Society [17] for weathering soil ground, the new filling material is expected to be utilized in the range that satisfies the standard design criteria.

3.4. Static Load Tests and Axial Load Transfer Analysis from Static Load Tests. Figure 7 shows the distribution of the axial forces according to the load-depth in the cement milk and the new filling material between the PHC pile and the earth wall. With loading of less than 60 ton, the two types of backfilling materials exhibit a similar axial force distribution and loaddepth curve. However, the axial load that was transferred to the ends of the pile is of 15.1 ton for cement milk and 24.8 ton for the new filling material at a load of 90 ton and 58.32 ton for cement milk and 91.6 ton for the new filling material under maximum load of 150 ton. In other words, the backfilling material that was made with the new filling material has a more effective transfer of the axial load to cement milk with a growth of depth under a high axial load. In the case where the cement milk that is injected into the surrounding pile consists of a poor mix, some of the cement milk escapes into

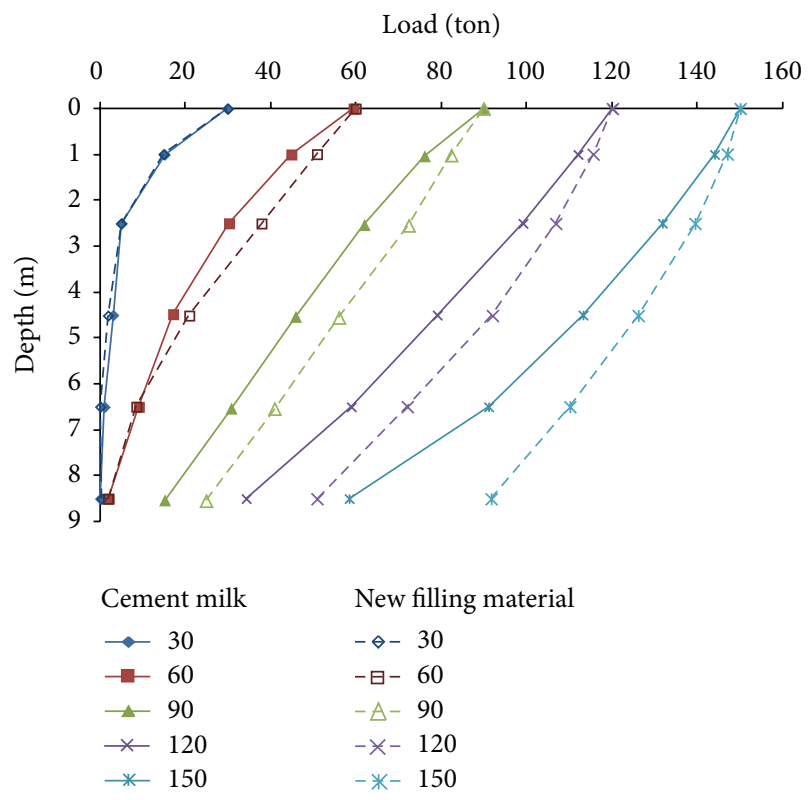

Figure 7: Axial load distributions according to load-depth.

the surrounding ground, and some of the surrounding pile from the ground level is not filled $[18,19]$. On the other hand, the ratio of loss of the new filling material is small due to the high viscosity of the soil.

3.5. Bond Capacity Assessment. Figure 8 shows the pullout test that was conducted in order to evaluate the bond capacity between the skin of the pile and the new filling material consisting of cement milk and waste soil produced in construction work. Three samples of each material were used in this experiment, and the average values for each of the test results are shown in Figure 9. The slip length of the specimen for the two types of material was similar at $8.45 \mathrm{~mm}$ 
TABLE 7: The actual amount of injected filling materials [for a pile $9.0 \mathrm{~m}$ ].

\begin{tabular}{lccccc}
\hline Type & Cement $(\mathrm{kg})$ & Water $(\mathrm{kg})$ & Soil $(\mathrm{kg})$ & Solidifying agent $(\mathrm{kg})$ & Superplasticizer $(\%)$ \\
\hline Cement milk & 590 & 490 & - & - & - \\
New filling materials & 98 & 133 & 415 & 0.25 & 0.03 \\
\hline
\end{tabular}

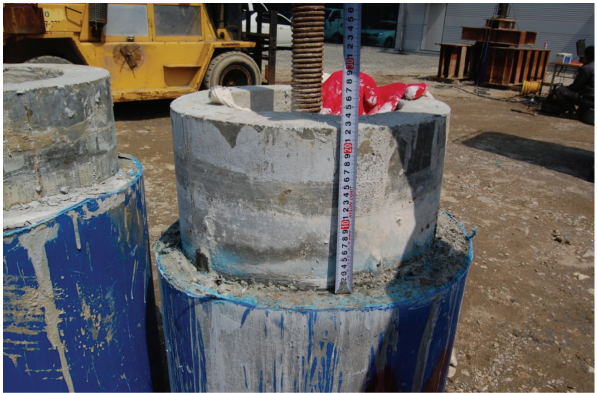

(a) Cement milk

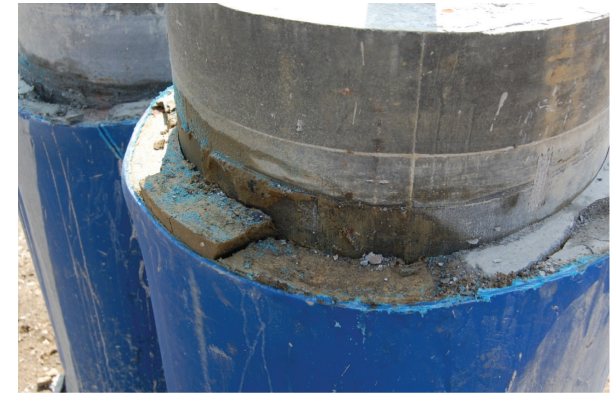

(b) New filling material

FIGURE 8: Failure shape using a pull-out test.

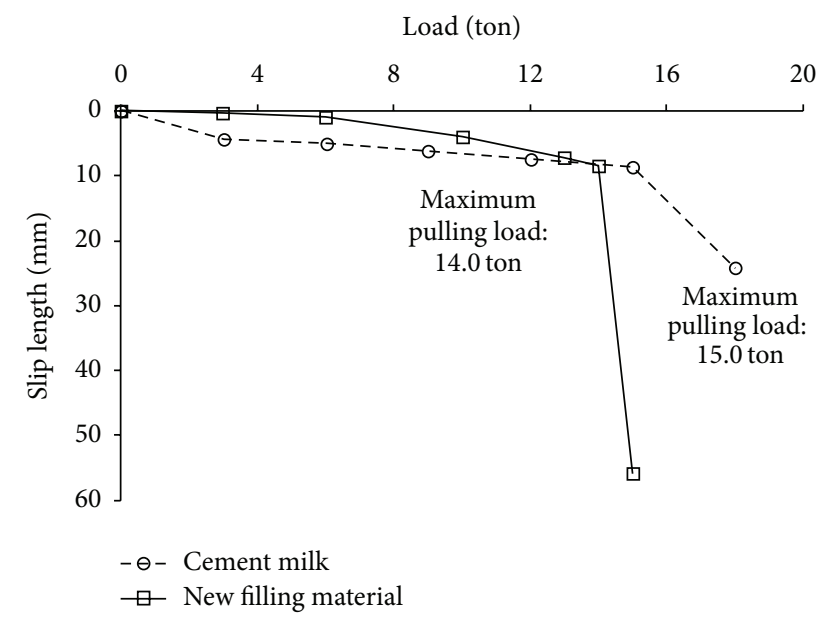

FIGURE 9: Bond capacity result from the pull-out test.

for the new filling material and $8.51 \mathrm{~mm}$ for cement milk. The unit resistance of the new filling material was 10.4 tonf $/ \mathrm{m}^{2}$, and the unit resistance of the cement milk was 11.19 tonf $/ \mathrm{m}^{2}$. Moreover, the maximum pulling load of the new filling material was satisfied at about $93 \%$ of the value of the cement milk. When the vertical load applied to the concrete structure where four sides are restrained, shear forces between the concrete surface and the surrounding materials is limited to receive a great influence on the characteristics of the surrounding materials [20]. After completing the test, shear failure was confirmed to occur in one of the specimens of the new filling material. In the case of the cement milk, a significant amount of bleeding occurred after the cement milk was poured. Although no additional injection of the cement milk was carried out during the actual pile construction, the cement milk was completely filled up to a height of $950 \mathrm{~mm}$ of the PVC cylinder to the same area of the pile skin by the two backfill materials. In addition, an average of $69 \%$ more cement milk was injected than was designed and considering the conditions at the actual site, much of the cement milk will be lost due to the high permeability of the soil.

3.6. Economic Feasibility Analysis. Table 7 shows the actual amount of injected filling materials for each pile. For the method using the new filling materials, although the use of solidifying agent of $0.25 \mathrm{~kg} /$ each pile and superplasticizer of $0.0294 \mathrm{~kg} /$ each pile was required, the amount of cement could be reduced by $492 \mathrm{~kg} /$ each pile in comparison to the cement milk. As a result, the suggested method could reduce the total construction cost by as much as $25 \%$ compared to the precious method.

\section{Conclusion}

A new filling material was developed using waste soil and a very small amount of cement in order to recycle waste soil generated from pile work, reduce the amount of cement used during construction, and lower costs. A basic experiment was carried out in a laboratory to test various parameters, including the flowability, compressive strength, and bond strength. These results indicate that the new filling material can be applied in the field, and the following conclusions are drawn for this new material:

(1) The mixing proportion that is suggested in this study to recycle waste soil is the optimal ratio needed to effectively fill the bore-hole. Also, bleeding rarely occurred for the new filling material when compared to cement milk. The new filling material addresses the limitations of using cement milk, such as the problem whereby the bore-hole is not adequately filled due to the loss of cement to the ground around the piles with sandy soil with a high permeability as well as the problem of a poor mix due to dilution when there is a high groundwater level. 
(2) At 28 days, the compressive strength of the new filling material was $7.23 \mathrm{MPa}$, which was $31 \%$ less than that of the cement milk. However, the 7.23 MPa value is greater than the value presented by Miki et al. [13], and the value for the compressive strength level of 10.45 MPa of cement milk obtained by the Expressway and Transportation Research Institute [15] therefore seems to be too conservative.

(3) After restriking on the two types of materials, the CSX and EMX values of the specimen with waste soil were smaller than those of cement milk, but this was satisfied within the allowable driving stress and the stress of materials was found to be within the allowable stress of the PHC piles according to the corresponding standard.Also, the average unit frictional resistance of the new filling material was $95 \%$ that of cement milk, but the 7.94 tonf $/ \mathrm{m}^{2}$ value is very stable and may be very conservative within the limited maximum value ( $\mathrm{fs} \leq 0.1 \times \mathrm{Ns}$, only in case of the weathering soil), according to an equation proposed by the Korea Geotechnical Society [17].

(4) In the pull-out test, the slip lengths of the new filling material and the existing cement milk were very similar, but the unit resistance between the two materials showed a difference of about $7.5 \%$. In addition, since the maximum pulling load of the new filling material was 14.0 ton, it was about $93 \%$ that of cement milk. Overall, the new filling material showed a reduced performance when compared to the specimen with cement milk, but considering the method used to inject cement milk in the field, the performance difference between the two backfill materials may not be significant.

(5) For the on-site application, the recycled waste soil should have proper particle size and viscosity in order to prevent the pipe blockage of injection equipment. Thus, it seems that the suggested method in this study is more appropriate for soil conditions such as weak sandy soil, viscous soil, and weathered soil than soft rock mass and weathered rock mass.

In general, the performance of the backfill using waste soil is slightly reduced relative to that of cement milk. However, the results are within the standard criteria for the structure foundation design. In addition, economic benefits could be identified, including cement savings of about $80 \%$ relative to the amount necessary with the conventional injection method in addition to the reduction in transportation costs since waste soil does not need to be removed from the construction site. However, this result is only limited to weathered soil.

\section{Competing Interests}

The authors declare that there are no competing interests regarding the publication of this paper.

\section{Acknowledgments}

This research was supported by the 2016 scientific promotion program funded by Jeju National University.

\section{References}

[1] C. Heejeong, Analysis of bearing capasity equation by load test results in bored piles [M.S. thesis], Yonsei University, Seoul, Republic of Korea, 2008.

[2] C. Soogeun and K. Hyungkeun, Design and Construction Manual of Large Diameter PHC Piles, ENGBook, 2013.

[3] Y. Jeawook, Building a construction management system for PHC pile in an apartment house [M.S. thesis], KyungHee University, Seoul, Republic of Korea, 2003.

[4] P. Youngho, K. Nagyoung, and Y. Jeonghoon, "Design and construction of SIP method," Report GE-04-06, Expressway and Transportation Research Institute, Korea Expressway Corporation, 2004.

[5] O. Kusakabe, M. Kakurai, K. Ueno, and Y. Kurachi, "Structural capacity of precast piles with grouted base," Journal of Geotechnical Engineering, vol. 120, no. 8, pp. 1289-1306, 1994.

[6] Y. Hongxia, "Experimental study on mechanical property of soil-cement," in Proceedings of the 2nd International Conference on Electronic \& Mechanical Engineering and Information Technology, pp. 790-793, November 2012.

[7] M. N. Ibragimov, "Characteristics of soil grouting by hydro-jet technology," Soil Mechanics and Foundation Engineering, vol. 50, no. 5, pp. 200-205, 2013.

[8] M. Kawamura and Y. Kasai, "Mix design and strength of soilcement concrete based on the effective water concept," Materials and Structures, vol. 44, no. 2, pp. 529-540, 2011.

[9] H. Yang, "Experimental study on mechanical property of soilcement," in Proceedings of the 2nd International Conference on Electronic \& Mechanical Engineering and Information Technology (EMEIT '12), pp. 790-793, Shenyang, China, September 2012.

[10] M. H. Ouhadi, "Ettringite formation in soil-cement interaction process," in Proceedings of the International Conference on Electrical and Control Engineering (ICECE '11), pp. 5899-5901, Yichang, China, September 2011.

[11] "JHS A 313. Cylinder method for consistency test, Japan Road Association," 1992.

[12] ASTM International, "Standard Test method for expansion and bleeding of freshly mixed grouts for preplaced-aggregate concrete in the laboratory," ASTM Standards C940, ASTM International, West Conshohocken, Pa, USA, 2003.

[13] H. Miki, J. Iwabuchi, and S. Chida, "New soil treatment methods in Japan. TREMTI 2005-Communication C189," 2005.

[14] "JSCE F 522. Standard specification for concrete structuremix proportion of grouting mortar, Japan Society of Civil Engineers," 2007.

[15] Expressway and Transportation Research Institute, Highway Construction Guide Specification, Korea Expressway Corporation, Seoul, Republic of Korea, 2005.

[16] B. N. Isaev, S. Yu. Badeev, A. G. Lunev et al., "Strengthening of soils by soil-cement elements," Soil Mechanics and Foundation Engineering, vol. 47, no. 5, pp. 202-206, 2010.

[17] Korea Geotechnical Society, Design Criteria for Structure Foundations, Korea Geotechnical Society, Seoul, Republic of Korea, 2009. 
[18] H. Won-Pyo and C. Soo-Geun, "Estimation of frictional capacity of SDA augered piles in various grounds," Korea Society of Civil Engineers, vol. 27, no. 4, pp. 279-292, 2007.

[19] W.-P. Hong, J.-H. Lee, and S.-G. Chai, "Bearing capacity of SDA augered piles in various grounds depending on water-cement ratio of cement milk," Journal of the Korean Geotechnical Society, vol. 24, no. 5, pp. 37-54, 2008.

[20] Z. Cheng, Z. Chunfeng, and G. Hui, "Elastoplastical analysis of the interface between clay and concrete incorporating the effect of the normal stress history," Journal of Applied Mathematics, vol. 2013, Article ID 673057, 12 pages, 2013. 

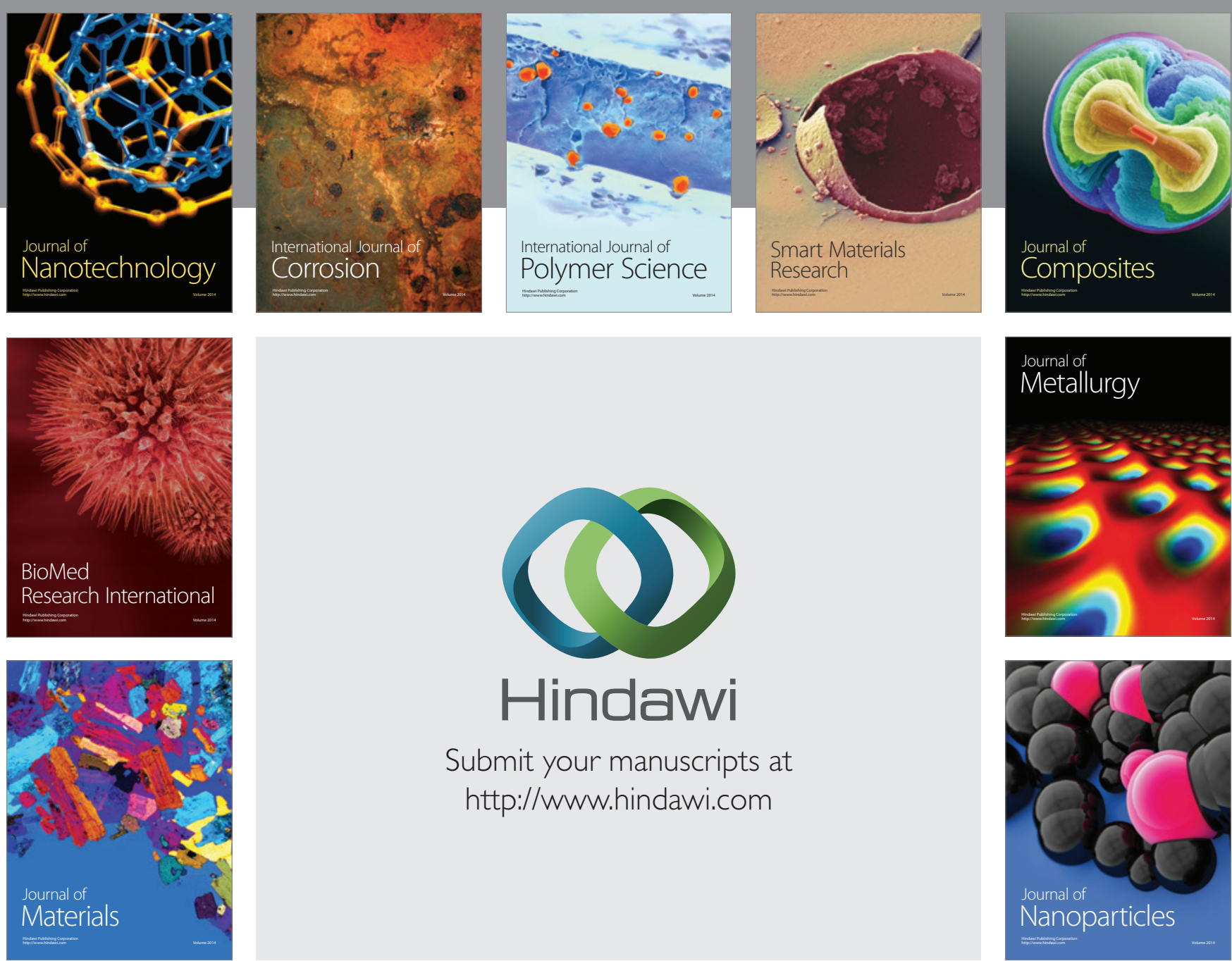

\section{Hindawi}

Submit your manuscripts at

http://www.hindawi.com

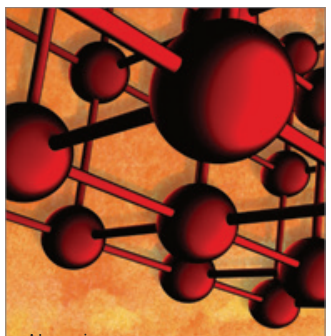

Materials Science and Engineering
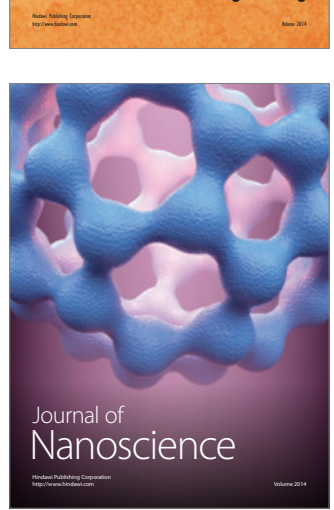
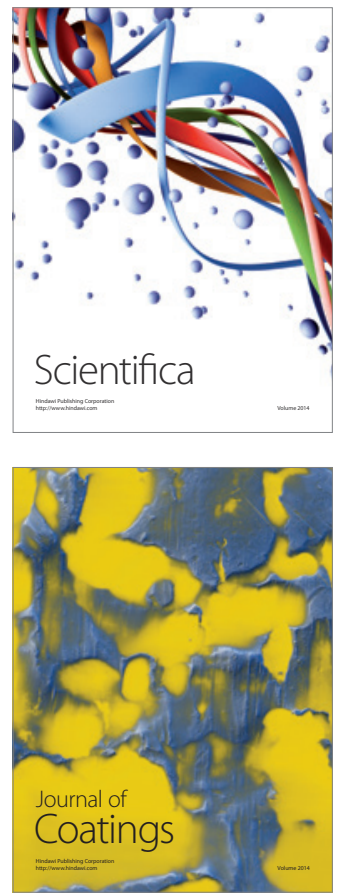
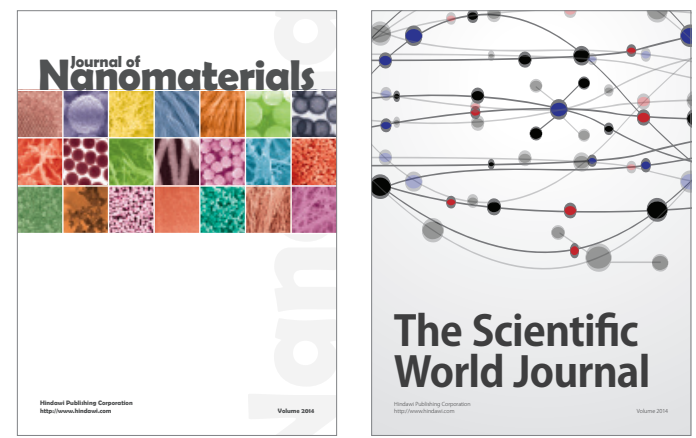

The Scientific World Journal
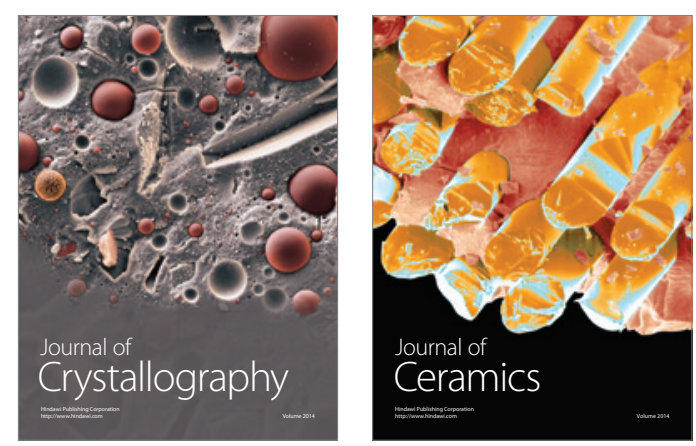
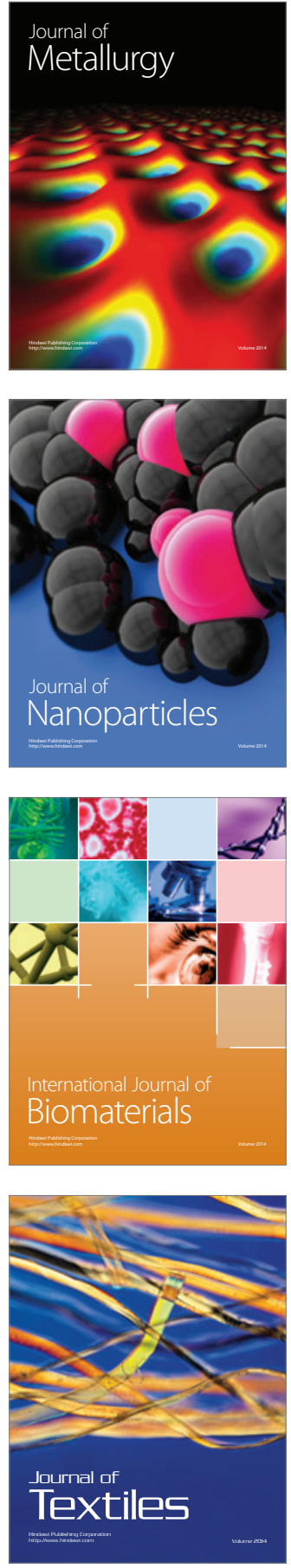